\title{
Mariana de Oliva, criada india de Santa Rosa de Lima: vida y textos*
}

Mariana de Oliva, Indian Servant of Saint Rose of Lima: Life and Texts

Paul Firbas ${ }^{\text {a }}$

State University of New York, Estados Unidos

DOI: https://doi.org/10.11144/Javeriana.cl25.moci paul.firbas@stonybrook.edu

ORCID: https://orcid.org/0000-0003-3977-2449

Recibido: 10 mayo 2019

Aceptado: 10 agosto 2019

Publicado: 13 octubre 2021

\section{Resumen:}

Este trabajo estudia los textos de la canonización de Santa de Rosa de Lima, preparados en esa ciudad entre 1617-1618 y 1630-1632, y sus primeras hagiografías publicadas en el siglo XVII en Europa. Mediante el estudio de diversos testimonios, narraciones e información, y de sus variantes, se reconstruye la participación de la criada Mariana de Oliva, "india ladina”, en la vida de Rosa y en la producción de su santidad, entendida como un fenómeno textual y como la manifestación de una cultura urbana multiétnica.

Palabras clave: Perú colonial, mujer, misticismo, amerindios, Lima.

\section{Abstract:}

This article studies Saint Rose of Lima's canonization texts prepared in that city between the years 1617-1618 and 1630-1632, as well as her first hagiographies published in the seventeenth century in Europe. The study compares diverse testimonies, narrations, information and their variants to reconstruct the participation of the domestic servant, Mariana de Oliva, a Spanishspeaking Indian or ladina, in Rose's life and in the production of her sainthood, understood as a textual phenomenon and as the manifestation of a multiethnic urban culture.

Keywords: Colonial Peru, women, mysticism, amerindians, Lima.

Los múltiples testimonios recopilados en la primera mitad del siglo XVII para la canonización de la criolla limeña Rosa de Santa María componen un particular mapa de la vida urbana en la colonia. Aunque la Iglesia contrarreformista había incrementado su control sobre la población en esos años, los procesos de santidad abrieron canales para la expresión de la devoción popular urbana y para la formación de símbolos de cohesión comunitaria. Así, la canonización de Santa Rosa fue probablemente el acontecimiento más importante en la vida de Lima a finales de ese siglo, junto con el devastador terremoto de 1687, que seguramente profundizó el vínculo afectivo con la santa limeña, patrona entonces de una ciudad en ruinas. La historia de su vida y la de los textos que la canonizaron no puede disociarse de las tensiones de su entorno colonial, aunque el discurso oficial haya minimizando sus rasgos locales para producir una imagen clásica de virgen-santa. Sin embargo, si estudiamos los documentos de la canonización, compuestos de decenas de testimonios de voces limeñas que repiten un mismo guion narrativo, y los cotejamos con las primeras hagiografías impresas en la época, aparecen diferencias y matices que nos permiten recuperar algo de la devoción popular indígena y su agencia en la formación de la patrona de Lima. ${ }^{1}$

En este sentido, el presente trabajo explora — en cierta forma a contrapelo- el archivo eclesiástico de la canonización de Santa Rosa para recobrar la participación indígena en lo que se ha entendido como un proceso de legitimación de los intereses criollos. No se trata de corregir esa lectura, que juzgamos correcta, sino de visualizar otros agentes y otros posibles proyectos que se sumaban al complejo fenómeno de la espiritualidad femenina criolla en la ciudad virreinal. El archivo santarrosino registra excepcionalmente la vida cotidiana de las mujeres indias dentro de las casas familiares criollas. En esos espacios domésticos,

Notas de autor

a Autor de correspondencia. Correo electrónico: paul.firbas@stonybrook.edu 
regidos por el orden español y criollo, se va consolidando lo que será una larguísima tradición de convivencia, complicidades e inobjetables jerarquías y dominación; pero también un campo complejo de afectos y aprendizajes bidireccionales, los cuales evidencian que en la convivencia doméstica y en sus prácticas históricas - la cocina, las labores de costura, la oración, etc. - se filtraban, y no sin equívocos, costumbres y palabras indígenas y, con ellas, sus formas de entender el mundo. ${ }^{2}$

El propósito de este estudio es ofrecer una entrada nueva a un archivo ya conocido - de enorme complejidad e intereses - que al ser releído a contrapelo arroja algunas luces sobre la importancia de Mariana de Oliva, sirvienta indígena, en la vida de Rosa y su santidad, y esboza un mapa interior de la ciudad, revelando el orden dentro de sus solares y sus conexiones con el mundo indígena. La micropolítica doméstica ha conservado con más tenacidad la moral del sistema colonial. ${ }^{3} \mathrm{Su}$ opacidad e intimidad le han permitido mantener sus características básicas por siglos, aunque la política visible se haya transformado en sistemas republicanos y democráticos.

La metodología se inspira en el trabajo de la crítica textual y el cotejo de variantes, aplicados aquí a las diversas versiones registradas en los procesos eclesiásticos limeños y a las primeras hagiografías publicadas en Europa, incluyendo los indicios que dejan los cambios de vocabulario y las pequeñas modificaciones en las descripciones y las narrativas. Estas diferencias suelen estar condicionadas por los distintos registros discursivos y, sin duda, por el lugar de enunciación, es decir, por las tradiciones invocadas, las afiliaciones y aspiraciones del hablante y los agentes eclesiásticos.

Con este procedimiento se espera obtener información y recuperar algo de la experiencia de la participación de Mariana en la vida de Rosa y en su canonización, es decir, en la inserción de Mariana en una textualidad eclesiástica que respondía, principalmente, a intereses criollos. Se trata, en última instancia, de "exprimir" el archivo para entender mejor la agencia de la mujer indígena en la ciudad colonial y cómo la economía de la santidad barroca integraba en su canon la devoción y espiritualidad popular de una ciudad multiétnica. ${ }^{4}$

\section{Textualización}

El acopio documental para la canonización de Rosa empezó inmediatamente después de su muerte —o quizá durante su agonía-, acaecida a finales de agosto de 1617. El ascenso a la santidad se inició con una extensa y apurada investigación y recopilación de 78 testimonios que produjeron el Primer proceso ordinario(PO). Este documento fue enviado a España en 1618, donde se tradujo, o se "transmutó", en latín para ser remitido a Roma. Los testimonios de este primer proceso respondieron, como era común, a un cuestionario unificado. Así, todas las deposiciones repasaron, en principio, los mismos 32 aspectos de la vida de Rosa. Como el cuestionario incluía también una narrativa — no solo una lista de preguntas-, puede considerarse que operó como un guion para los testigos. Dentro de este escenario textual fuertemente enmarcado, se pueden notar, no obstante, algunas variantes en los detalles secundarios del discurso de la santidad. Se trata de algo así como el ruido de fondo que nos deja entrever la vitalidad de un mundo doméstico diverso que, aunque minimizado, constituyó parte del soporte sobre el que se levantó la canonización.

En 1625 el expediente de Rosa fue evaluado positivamente en Roma, con carácter de santísimo, pero se observaron irregularidades técnicas en la recopilación de los testimonios (Hart, "The Biographical” 234). Así, en 1630 se dio inicio formalmente al proceso apostólico (PA) y se procedió, en Lima, a la preparación de un nuevo cuestionario y nuevas deposiciones de testigos, realizadas entre los años de 1630 y 1632. Doce declarantes del primer proceso volvieron a rendir testimonio (Hampe 44). Consecuentemente, en las narrativas del proceso ordinario y del apostólico se observan diferencias importantes, como veremos más adelante, que responden a dos momentos, que tienen unos trece años de diferencia entre sí. En el año 1634, cuando el nuevo expediente limeño estaba ya en Europa, el proceso se detuvo por varias reformas eclesiásticas que regulaban la validación de los milagros y le daban más control a la curia pontificia en la gestión de 
la santidad. Ese año, el papa Urbano VIII prohibió iniciar procesos hasta que no hubieran transcurrido cincuenta años desde fallecimiento del candidato, con lo cual el caso de Rosa quedó suspendido por treinta años. $^{5}$

En esos años de espera sucedió un hecho textual que seguramente fue un instrumento que usó la Orden de los Predicadores para precipitar la canonización de Santa Rosa: en 1664, se publicó en Roma una extensa biografía en latín de la mística limeña, Vita mirabilis et mors pretiosa, evidentemente documentada con los materiales del proceso apostólico. ${ }^{6} \mathrm{Su}$ autor fue Leonardo Hansen, un dominico inglés que pasó a la historia de las letras justamente por esa, su única obra. Stephen Hart ha argumentado en 2017, con razones documentadas, que Hansen fue un pseudónimo, muy probablemente del dominico Vincent Torre, padre provincial inglés de ascendencia española que habría ocultado su nombre debido a las persecuciones que sufrían los católicos en Inglaterra. Esta primera hagiografía tuvo múltiples reediciones y traducciones y dio pie a varias refundiciones, todas publicadas en el lapso de pocos años, antes e inmediatamente después de la beatificación de Rosa en 1668 y de su canonización en 1671 . $^{7}$

Cuando se reabrió el proceso en 1663, cuatro años antes de que se cumpliera el plazo, el ambiente teológico había cambiado considerablemente. La Iglesia había adoptado una nueva economía médico-legal que regía la evaluación de los milagros de los aspirantes a la santidad, lo que explica la criba final de los portentos atribuidos a Rosa y los pocos que fueron canonizados. ${ }^{8}$ Tenían más credibilidad los milagros que implicaban una cura que podía verificarse médicamente. Además, en esos años solo un $17 \%$ de los casos de santidad femenina fueron aprobados, lo que revelaría un distanciamiento institucional de las formas femeninas del misticismo (Hart, "The Biographical" 240), como las practicadas por el grupo de mujeres criollas y españolas del entorno de Rosa, cuya personalidad más visible fue Luisa Melgarejo.'

Para el proceso final de canonización en Roma se designó en 1659 al dominico limeño Antonio González de Acuña, catedrático en San Marcos de teología moral y prior del convento de Huánuco (Meléndez 693-694). En 1665, escribió un compendio del libro de Hansen, publicado el año de la beatificación, llamado Rosa de S. Maria Virgo Limensis. El año de la canonización publicó en castellano su Rosa mistica, vida y muerte de Santa Rosa de S. María Virgen (Roma, 1671), adaptación también del libro de Hansen, pero con importantes matices criollos.

De los 119 milagros propuestos por González de Acuña, muchos describen el consumo curativo (milagroso) de la tierra alrededor de la tumba de Rosa. La lista se redujo a 23 milagros en 1665, casi todos de curaciones, incluida la de una criada, probablemente india, de nombre María (Hart, Santa Rosa 81-108). Finalmente, solo nueve fueron aceptados, todos de carácter médico-curativo. Sin embargo, la cultura popular conserva hasta hoy las narraciones milagrosas recogidas por las hagiografías publicadas antes de la canonización. Uno de los nueve milagros canónicos narra la curación de doña Magdalena Chamiso, india principal del pueblo de Chincha, quien viajó a Lima y consiguió reliquias y tierra de la tumba de la santa, con las que curó sus piernas tullidas (Hart, Santa Rosa 135; Hart, Edición crítica 101 [PA]). ${ }^{10}$

Desde la perspectiva que nos interesa en este trabajo, destacamos el hecho de que, desde el proceso ordinario, los documentos para la canonización de Santa Rosa incluyeron testimonios de mujeres allegadas a la familia y su entorno doméstico, entre ellas varias criadas indias y algunas esclavas negras y mulatas libres, lo cual no era excepcional. Fernando Iwasaki ha publicado una útil tabla comparativa de los testigos que participaron en ocho procesos diocesanos en el Perú del siglo XVII. Allí puede verse, por ejemplo, que, en el proceso de fray Juan Macías (1645), el 74\% de los testigos fueron mujeres laicas, frente al $42 \%$ en el de Rosa de Santa María (1617-1618). Lo que sería excepcional en nuestro caso es que podemos entrever el peso que habría tenido Mariana no solo en la vida de Rosa, sino en la producción de su santidad, a pesar de que los procesos y hagiografías hayan diluido su agencia. Todo esto nos conduce a reconsiderar la proximidad de las esferas criolla e indígena en las prácticas domésticas y la devoción religiosa en Lima hacia principios del siglo XVII. 


\section{Mariana de Oliva}

Hasta donde sabemos, no se ha estudiado la vida de la "india ladina” Mariana de Oliva. Lo poco que podemos conocer de ella se limita, por ahora, a los textos interesados en la canonización de Rosa, en la cual Mariana juega un papel centralísimo como testigo de la vida doméstica de la santa por muchos años. Una lectura atenta de los testimonios de la misma Mariana, de los de la madre y del hermano de Rosa, más algunas breves narraciones de los milagros de Rosa en la ciudad, nos permiten componer una imagen fragmentaria pero significativa que trasciende su función "doméstica" y de confidente de los ayunos y mortificaciones de la santa en las hagiografías publicadas en el siglo XVII.

Para poder acercarnos a la trayectoria de vida de Mariana, conviene presentar de modo esquemático la vida de la santa, que podríamos dividir en cuatro períodos:

1. De 1586 a 1596: nacimiento y primera infancia en la ciudad de Lima.

2. De 1596 a 1603(?): la familia Flores Oliva vive en Quives (Canta), en una sierra cerca de Lima, por el trabajo del padre como administrador de una mina de plata. Rosa recibe en Quives el sacramento de la confirmación en 1599, durante la visita del arzobispo Toribio de Mogrovejo a esa zona de marcada resistencia a la evangelización. ${ }^{11}$

3. De 1603(?) a 1612: regreso a la casa familiar en Lima. Rosa se recluye en una ermita o pequeña celda construida en el jardín.

4. De 1612 a 1617: Rosa deja la casa familiar y se traslada a la de sus tutores, los esposos Gonzalo de la Maza y María de Uzátegui, donde fallece. ${ }^{12}$

La vida de Mariana - lo que podemos recuperar de ella- puede reunirse en un párrafo breve, que luego pasaremos a explicar: Mariana nació hacia 1585 en Lima. Vivió en casa de los Flores Oliva desde los dos años y fue la criada personal de Rosa. No conoció a sus padres y fue analfabeta (no pudo firmar sus testimonios). Tuvo dos matrimonios y al menos un hijo, probablemente de su segundo esposo. En 1611, a los 26 años, dejó la casa de los Flores Oliva, vivió en varias casas y en el barrio de San Lázaro con su segundo marido, el sastre indio Juan Jiménez. Después del fallecimiento de Rosa, Mariana obraba curaciones o hacía milagros como mediadora de la santa. Seguía viviendo en Lima en 1631, el último año del que tenemos noticias fechadas de ella.

La primera noticia de Mariana de Oliva aparece en el proceso ordinario (PO) en 1618. En general, los documentos eclesiásticos usan el apellido de la madre de Rosa para identificarla. Mariana declara en 1618 que está casada con Cristóbal Fonseca, "fardero, residente de esta ciudad", ${ }_{13}^{13}$ que entró a servir en casa de los Flores Oliva a la edad de dos años, siendo de la misma edad de Rosa, y "que se ha criado en casa de los padres" de la santa. Reconoce tener 32 años, "pocos más o menos”. En esta primera declaración, no se menciona que Mariana sea india. Sobre su residencia, en su primera respuesta, Mariana indica que desde que entró a servir en casa de los Flores Oliva "hasta ahora he estado en ella" (Primer proceso 402 [PO]).

La segunda información sobre la vida de Mariana está en su declaración de 1631. En el encabezado se especifica que Mariana de Oliva era "india ladina”, pero ella se define como "natural y criolla de esta dicha ciudad”. ${ }^{14}$ En su respuesta a la sexta pregunta, Mariana revela que desde 1611 estaba casada con el sastre indio Juan Jiménez, natural de Manta, ${ }^{15}$ y que desde entonces ya no vivía en casa de los Flores Oliva, pero iba todos los días a visitar a Rosa "por no hallarse con otra persona por haberse criado con ella" (Hart, Edición crítica $409[\mathrm{PA}])$. En esta declaración revela que nunca conoció a sus padres y se infiere que tuvo, al menos, un hijo.

En las preguntas de 1618 sobre el enterramiento de Rosa, las respuestas de Mariana muestran que ella tenía su propia vida de familia, ajena a los Flores Oliva, aunque no lo reconozca en este, su primer testimonio. Es curioso que Mariana contestara que ella no asistió al entierro "porque fue después de comer" (Primer proceso 
27 [PO]). En 1631, cuando recuerda la muerte de Rosa, dice que no estuvo presente "porque había ido a estar con un hijo suyo que estaba enfermo" (Hart, Edición crítica 410 [PA]).

Mariana no dijo - o no permitieron que dijera - la verdad sobre sus "matrimonios" y su residencia porque esto habría desautorizado su declaración. Hasta ahora, los estudios no han reparado en las evidentes contradicciones de sus dos testimonios. Una tercera fuente de información en este sentido la encontramos en una breve narración sobre Isabel Mejía de Arévalo, comadre de los Flores Oliva, testigo en el proceso ordinario, viuda de 60 años en 1618 y amiga de toda la vida de la familia. En la biografía latina de Hansen y en la traducción de Jacinto Parra, La bienaventurada Rosa, se cuenta que doña Isabel "tenía por criada a Mariana, a quien, estando enferma, de caridad servía de enfermera Rosa” (Parra 293; Hansen 222). Es, por tanto, muy posible que después de 1611 Mariana haya pasado a servir en casa de Isabel Mejía.

En el apéndice de los libros de Hansen y Parra, donde se narran los milagros post mortem de Rosa, se reconfirma la información sobre la residencia de Mariana. Allí se cuenta que María de Vera, española y viuda de Alonso Núñez, estando enferma le "pidió a su vecina Mariana, india y mujer de un sastre (la cual en sus primeros años se había criado con Rosa) le trajera una imagen de la Virgen [Rosa] pintada en un lienzo", con la cual sanó (Parra 455; Hansen 349). En sus declaraciones de 1632, María de Vera precisó que "vive en una casa alquilada en esta ciudad en el barrio de San Lázaro junto a Jiménez el rastrero" ${ }^{16}$ Dio testimonio de haber tenido mucha amistad con los Flores Oliva y dijo que estando enferma se había sanado con un "cuadro de su rostro" (de Rosa), que le había pedido a Mariana (Hart, Edición crítica 747 [PA]). ${ }^{17}$

Este último dato nos permite situar a Mariana en la ciudad cuando dejó el solar de los Flores Oliva hacia 1611: vivió en varias casas y en el barrio de San Lázaro con su marido sastre, el indio Juan Jiménez. San Lázaro era un barrio pobre del otro lado del puente sobre el Rímac, con una significativa población negra e india. Fuera del espacio doméstico de Rosa, Mariana mantenía su relación con la santa, inclusive después de 1617, a través de las imágenes y actuando como su mediadora, como lo cuenta también María de Oliva, según veremos más adelante.

Podemos conjeturar que el primer matrimonio de Mariana, con el fardero Cristóbal Fonseca, fue una solución eclesiástica para "arreglar" su estado y residencia, considerando el valor de su testimonio, pues ella había sido la única testigo de muchos episodios de la vida doméstica de Rosa. Mariana habría mantenido desde 1611 una relación con su "marido" sastre, pero sin matrimonio. Por tanto, su textualización en 1618 implicó casarla con el fardero Fonseca. Ese enlace ya no existía en 1631, cuando se declara "casada" con Jiménez, y admite que "seis años antes que muriera [Rosa], se casó con el dicho su marido [en 1611] y vivía en diferentes casas” (Hart, Edición crítica 409 [PA]).

Regresemos al esquema de la vida de Rosa, propuesto arriba. En su primera infancia, Mariana aparece en varios episodios mencionada o aludida en los procesos y hagiografías, por ejemplo, cuando ayudaba a Rosa en sus juegos o tempranas penitencias a los cuatro o cinco años, poniéndole adobes sobre los hombros en el huerto de la casa familiar (Hart, Edición crítica 410 [PA]). En la segunda etapa, que es la que trascurre por unos cinco años en el pueblo de Quives durante la adolescencia de Rosa, no tenemos datos directos de las acciones de Mariana. Todo indicaría, sin embargo, que, siendo la criada personal de Rosa, viajó con la familia a la sierra. En la textualización (y canonización) de ese viaje, solo se recuerda el excepcional sacramento de la confirmación que recibió la santa en ese pueblo y el episodio curioso y terrible del tullimiento de Rosa, contado como un ejemplo de obediencia. Allí se narra el tratamiento que le impuso su madre, atándole pieles de buitre, que le llagaron las piernas a la joven. En las declaraciones del PO de 1618, ni la madre de Rosa ni Mariana mencionan que el tullimiento y tratamiento sucediera en Quives; mientras que en 1631 la madre sí declara que "estando en

un pueblo de Canta, en un obraje, se tulló de pies y manos la dicha su hija” (Hart, Edición crítica 177 [PA]). ${ }^{18}$

El período de Quives (Canta) ha sido estudiado agudamente por Luis Millones como los "años oscuros" de Santa Rosa, siguiendo los indicios de posibles contactos entre la santa y el mundo indígena. En su libro Una partecita del cielo, enmarcado en sus investigaciones sobre religiosidad popular andina, Millones llamó la atención sobre el hecho de que, desde las primeras hagiografías, Rosa aparece como una mujer 
estrictamente urbana, aunque sepamos que vivió en las sierras de Lima y que esa experiencia "debió influir en su vida posterior" $(38,51) .{ }^{19}$ Sobre la vida de Mariana, no aporta nuevos datos, pero destaca aquello que, aunque siendo conocido, no se le había prestado suficiente atención: Rosa y Mariana eran compañeras y confidentes, y se comunicaban todos los días, como lo recuerda Mariana en su declaración. Sin embargo, Millones apunta también la ausencia de voz de Mariana en las hagiografías, a pesar de que estas incluyen escenas dialogadas, y señala el hecho de que aparezca solo en "situaciones de martirio", es decir, en episodios de padecimiento, aunque Rosa también tuvo "espacios de gozo espiritual y transportes místicos en que las visiones sobrenaturales pudieron ser compartidas por parientes y amigos", "Mariana no aparece relacionada con ninguno de estos episodios". Finalmente, Millones resume la imagen de Mariana en los textos como una figura de inversión: la "agreste" india opuesta a la cultivada rosa (42, 40-46). La biografía de Hansen, ya citada en la traducción de Parra, la presenta así: "Servía en su casa Mariana, india de nación y en la condición agreste y rústica” (37). ${ }^{20}$ Desde el punto de vista del orden español, la inversión entre la agreste india y la cultivada rosa podía extrapolarse a las "naciones" que ambas representaban: la oposición entre las idolatrías de la sierra (agreste) frente a la santidad de la ciudad de los Reyes. ${ }^{21}$ Teodoro Hampe registró setenta casos de personas que fallecieron en Lima con "olor a santidad" entre finales del siglo XVI y mediados del XVII, y en esa "efervescencia religiosa" se promovieron más de cuarenta procesos diocesanos (13, 49). Millones resume la oposición entre el espacio urbano y el serrano rural en una frase: "Santos en Lima e idólatras en Huarochiri" (37).

Regresemos a las etapas de la vida de Rosa, que nos ayudan a entender su imbricación con Mariana. En la tercera etapa (1603[?]-1612) es cuando se intensifican las prácticas corporales y místicas de Rosa y la asistencia de Mariana, en varios niveles. Las narraciones sobre los cilicios de Rosa, la dureza de las tablas de su cama o almohada, sus ayunos y su reclusión en un pequeño retrete o celda construida por su hermano pertenecen a esta etapa de maduración que antecede a las mudanzas de ambas mujeres. Mariana fue testigo de los usos privados de la "cadena de hierro y diversos cilicios que usaba" Rosa y de la corona de espinas, por eso la madre llama a Mariana "secretaria" de la santa (Primer proceso 300, 382 [PO]). ${ }^{22}$ Como veremos más abajo, los testimonios de María de Oliva, de Mariana y de Hernán, el hermano de Rosa, son los más ricos en la transmisión de lo que fue la experiencia doméstica cotidiana de estas dos mujeres que, aunque confidentes y amigas, eran también un reflejo del orden colonial.

En la última etapa, durante la adultez de Rosa (1612-1617), Mariana ya no vivía en casa de los Flores Oliva, pero Rosa tampoco. La mística decidió mudarse poco después de Mariana. Es decir, cuando su criada se unió con el sastre Jiménez y pasó a vivir en otras casas, Rosa tomó una decisión de alguna manera semejante, dejando su entorno doméstico y cambiando de familia, para vivir con Gonzalo de la Maza y María de Uzátegui, a quienes la beata llamaba padres. ${ }^{23}$ Creo que el hecho de las mudanzas en paralelo, inadvertido por la crítica, nos da un cuadro más completo de la gran proximidad que había entre ambas mujeres y de la importancia que pudo haber tenido en Rosa el cambio de vida de Mariana hacia 1611.

El testimonio del anciano padre de Rosa, Gaspar Flores, es bastante escueto y no oculta que "como este testigo era hombre" desconocía muchos detalles de la vida espiritual y los trabajos de su hija (Primer proceso 399 [PO]). El testimonio de la monja Catalina de Jesús, amiga de Rosa que pasó noches junto a la mística en la pequeña celda del jardín, corrobora algo de esa información doméstica, pero nada dice directamente de Mariana (Primer proceso 392-397 [PO]).

\section{Recuerdos de casa y ciudad}

El testimonio de Hernán Flores de Herrera, hermano de la santa, en el proceso ordinario (1618) es excepcional por la intensidad y afectividad de sus recuerdos domésticos. En su respuesta a la pregunta sexta, sobre los ayunos y comida de Rosa, Mariana aparece indirectamente mencionada como "la persona que le 
hacía [a Rosa] su guisado" con amargas hojas de granadilla, y como la "muchacha de servicio" que recogía cómplice la servilleta de Rosa donde iban envueltos los pescaditos fritos o "cachuelos" que fingía comer ante su madre. En estos recuerdos de ayunos y cocina, el hermano cita finalmente con nombre propio a la sirvienta, quien sacó del engaño a la madre de Rosa: "Después de su dichosa muerte, ha entendido de Mariana Oliva, de quien la bendita Rosa se fiaba, que cuando la obligaban que comiese algo, fingía que comía”. El testimonio del hermano recrea así las conversaciones y confesiones familiares de Mariana, a quien vuelve a mencionar como "secretaria" de los castigos corporales de Rosa. Hernán era dos años mayor que Mariana. Nunca se refiere a ella como india; la llama "muchacha de servicio", "persona", "secretaria" de Rosa (Primer proceso 523-524 [PO]).

María de Oliva, la madre de Rosa, es la voz más significativa detrás de la construcción de la narración canónica de la vida doméstica de su hija. En 1618, en su respuesta a la misma pregunta seis, la madre confirma que Mariana encubría las secretas penitencias de Rosa y era cómplice de sus ayunos:

Tenía prevenida a la dicha Mariana de Oliva, su criada, que le hiciese un guisado, que en esta tierra llaman locro, de hoja de una mata que llaman granadilla, que son muy amargas, y que porque no se echase de ver de lo que era, le mandaba echase en él unas papas, que son a modo de turmas de la tierra. (Primer proceso 279-380 [PO]) ${ }^{24}$

Mariana, en cambio, en su testimonio también de 1618, recuerda el episodio culinario así:

[Rosa le decía] que le hiciese un guisadillo que acá se llama locro, de hojas de granadilla, por ser muy amargas, y le mandaba que para disimilar pusiese en él unas papas deshechas [...]. Y esta testigo hacía este locrillo, como la santa se lo mandaba. (Primer proceso $403[\mathrm{PO}]$ )

Mariana matiza su guiso siempre con un diminutivo (guisadillo, locrillo) que no aparece en el testimonio de la madre. ${ }^{25}$

Siempre en 1618, a la pregunta siete, sobre la dureza de la cama de Rosa, la madre se refiere a "un cojinillo de cumbi, que es de llama, como paño" (Primer proceso 381 [PO]). Ante la misma pregunta, Mariana también recuerda "que [Rosa] usaba de una almohada de lana de cumbe", y no explica la palabra quechua (Primer proceso 404 [PO]). En la pregunta quince, tanto la madre como la criada recuerdan que Rosa se frotaba los ojos con ajíes, pero solo en el testimonio de Mariana se explica esta palabra "que en España llaman pimiento de Indias" (Primer proceso 385, 406 [PO]), lo que parece una evidente intervención de alguna de las manos que trabajaron en la transcripción de los testimonios orales y la creación del proceso ordinario. ${ }^{26}$ La mayoría de los usos lingüísticos que cargaban la vida doméstica de Rosa de referencias indígenas desaparecen en los testimonios del proceso apostólico de 1630-1632. Inclusive, la misma Mariana se refiere en 1631 a la comida de Rosa como "unas coles cocidas con agua de olla" (Hart, Edición critica 410 [PA]). ¿El camino a la santidad debía limpiarse del "agreste" léxico andino?

En el proceso apostólico, en 1631, la madre de Rosa hace su declaración ya como monja del nuevo monasterio de Santa Catalina en Lima, profetizado por su hija. En los trece años que separan los dos procesos, es evidente el aumento de la devoción popular y de los milagros atribuidos a Rosa. La primera mención que hace la monja-madre de la antigua criada es excepcional. Mariana aparece como obradora de milagros, por "intercesión" de Rosa, como si la vieja complicidad y confidencia entre ellas continuara. Creo que hasta ahora los estudios no han reparado en esta continuidad del servicio de Mariana y sus múltiples implicaciones. El episodio que narra la madre empieza con el recuerdo de una negra esclava de nueve o diez años que Rosa había comprado por cincuenta patacones, "para que sirviese a esta testigo, aunque [la niña esclava] estaba enferma de diferentes males" y agrega:

Después de muerta la dicha Rosa, le continuó el mal [a la esclava] y viendo que Mariana hacía tantos milagros por su intercesión con otros con la tierra de su sepultura, pidió un poco de dicha tierra y se la trajeron. Y con buena fe y esperanza de que por esta intercesión le había de sanar y dar salud, esta testigo mando a una mora que se llama Mariana india que la crió esta testigo en su casa, y muy devota y muy amiga de la dicha Rosa, y la dicha Mariana tomó un poco de tierra de la del dicho sepulcro y la puso en un vaso de agua y la dio a la dicha negrita a beber y, a la primera vez que la tomó, quedó buena y sana. Y 
lo estaba hasta que murió [a los] diez y siete años, de un resfriado murió la dicha negrita. Y asimismo sabe que Mariana obró otro milagro por intercesión de la dicha Rosa. (Hart, Edición critica 181-182 [PA] $)^{27}$

La cita es clara en señalar la imagen milagrera que se le atribuye a Mariana, que parece así continuar su relación de "secretaria" de Rosa, después del fallecimiento de la mística. La antigua criada aparece ya como una figura ajena a la familia Oliva, la madre la llama "mora" y la apellida "india". Esta designación se repite poco más adelante en el mismo testimonio, cuando María de Oliva recuerda los ayunos y los guisos que la criada le preparaba a Rosa, y cómo ella fue engañada por su criada e hija:

Y aunque se sentaba a la mesa, no comía de lo que se comía en ella, sino que se le había guisado de hierbas con unas papitas
que mandaba esta testigo hacer a una mora llamada Mariana india, que la criaron en casa de esta testigo. Y era una amiga de
la dicha Rosa con quien comunicaba y trataba sus secretos, la cual es casada con Juan Jiménez, indio sastre que vive en esta
ciudad. Y la dicha india, en lugar de hacer el dicho guisado de hierbas buenas comederas, le hacía de hojas de granadillas que
son amargas porque la dicha Rosa se lo pedía y rogaba así. Y esta testigo no lo probaba, entendiendo siempre que era de gusto
y de buenas hierbas. Y nunca lo manifestó la dicha india hasta que murió la dicha Rosa. Y, viéndola muerta, dijo la dicha
Mariana: "Ahora puedo hablar, porque la dicha Rosa me mandaba que no dijese nada de lo que hacía. Y ahora digo que si la
Rosa no es santa no hay santas en el mundo". (Hart, Edición crítica 188 [PA])

Es imposible saber si había algo de rencor en la madre-monja al recordar los engaños que tramaban su hija y su criada. Quizá, la unión y matrimonio de Mariana, casada con el indio sastre, haya marcado su alejamiento de María de Oliva. En un momento de su declaración, teñido de engaño, la madre introduce el relato de las humillaciones físicas que la criada le propinaba a Rosa, a pedido de la santa:

La cual [Mariana] le refirió a esta testigo que la dicha Rosa la mandaba que la acostase y pisase muchas veces, y le tendía en el suelo y le decía que le diese y pisase recio, la cual sentía mucho hacer la dicha Mariana, sino que se lo pedía con instancia la dicha Rosa y, como la quería tanto, acudía a darle gusto. (Hart, Edición crítica 188-189 [PA])

No podemos recuperar el tono de estas narraciones que cuentan engaños, obediencia y cariño. Se trata de un testimonio de madre - aunque ya recluida como monja - que le atribuye alguna responsabilidad a Mariana en los sufrimientos corporales de su hija. Este episodio de "humildad profunda" lo recoge Hansen en su hagiografía latina y lo reproducen sus traducciones y adaptaciones. Sin embargo, no aparece en los testimonios de Mariana, como era de esperarse. Solo lo cuenta la madre en 1631, aunque no en sus dos declaraciones de 1618. La incorporación de este episodio al canon hagiográfico puede deberse a que la madre, ya convertida en monja e hija de Santa Catalina de Siena, había adaptado sus recuerdos para que se ajustaran a los ideales de humildad de la santa italiana, considerando que la misma Rosa vivió imitándola, o bien a una interpolación de sus superiores dominicos, también interesados en resaltar la conexión con Santa Catalina. Por ejemplo, el francés San Francisco de Sales, en su Introducción a la vida devota, le explica a Filotea suavemente los rigores del camino ascético: "Muchas almas devotas, para mejor sujetarse a Dios, han humillado sus voluntades a las de sus mismas criadas y domésticos; lo cual Santa Catalina de Siena alaba infinitamente en sus Diálogos" (43). ${ }^{28}$

Al final de su declaración, sin embargo, María de Oliva cambia de tono y recuerda una escena familiar con su esposo y un gallo doméstico que Rosa hizo cantar. Es un recuerdo feliz que incluye a "Mariana india que vivía en casa" y agrega "la dicha Mariana india que vive hoy en esta ciudad, mujer de mucha virtud" (Hart, Edición crítica $202[\mathrm{PA}])$.

En resumen, el testimonio de María de Oliva de 1631 nos permite ver a Mariana después de 1617 moviéndose por la ciudad y participando activamente en la devoción popular de Rosa y en la producción de su santidad oficial. La antigua criada parece seguir conectada con su "amiga", ahora como mediadora de sus milagros. Asimismo, el testimonio de Mariana de 1631, donde aclara que ella se marchó de casa de los Flores Oliva seis años antes del fallecimiento de Rosa, debe servirnos para reconsiderar los motivos por los que la santa dejó también su casa familiar y pasó a vivir con el contador Gonzalo de la Maza y su esposa María de Uzátegui. 
Los documentos y hagiografías aquí estudiados contienen en sus variantes y matices una cantidad significativa de información y relatos menores que superaron el control y normatividad del discurso canonizante. Al estudiar esos detalles, entramos por la puerta falsa al archivo institucional y podemos sacar a Mariana del papel fijo que le asignaron los textos, y verla caminando como india y criolla por una ciudad cargada de una devoción religiosa integrada por diferentes naciones étnicas; podemos quizá escucharla, hablando con quienes le pedían la tierra curativa del sepulcro de la santa, cruzando el puente con una imagen de su patrona.

\section{Referencias}

Acosta, José de. Historia natural y moral de las Indias, edición crítica de Fermín del Pino-Díaz. Consejo Superior de Investigaciones Científicas, 2008.

Covarrubias, Sebastián de. Tesoro de la lengua castellana o española, editado por Ignacio Arellano y Rafael Zafra. Universidad de Navarra / Editorial Iberoamericana / Vervuert, 2006.

Del Busto Duturburu, José Antonio. Santa Rosa de Lima (Isabel Flores de Oliva). Pontificia Universidad Católica del Perú, Fondo Editorial, 2006.

Deusen, Nancy E. van. Las almas del purgatorio: el diario espiritual y vida anónima de Úrsula de Jesús, una mistica negra del siglo XVII. Pontificia Universidad Católica del Perú, Fondo Editorial, 2012.

Espitia, Pilar Consuelo. Queering the Andean Mystics: represiones, subversiones y deseos en las prácticas religiosas de la América colonial (Perú, siglos XVI-XVII). 2018. Stony Brook University, tesis de doctorado.

Estenssoro Fuchs, Juan Carlos. Del paganismo a la santidad. La incorporación de los indios del Perú al catolicismo, 1532-1750. Traducido por Gabriela Ramos, Instituto Francés de Estudios Andinos / Pontificia Universidad Católica del Perú / Fondo Editorial, 2003.

Ferrer de Valdecebro, Andrés. Historia de la maravillosa y admirable vida de la venerable madre y esclarecida virgen Sor Rosa de Santa Maria, de la Tercera Orden de Santo Domingo. Pablo de Val, 1666.

González de Acuña, Antonio. Rosa de S. Maria virgo limensis è tertio ordine SS. P. Dominici, Augustae Vindilicorum. Simonis Utzschneider, 1668.

-------. Rosa mistica, vida y muerte de Santa Rosa de S. Maria, Virgen de la Tercera Orden de Santo Domingo; natural de la Ciudad de los Reyes Metropoli del Reyno del Peru en las Indias Occidentales. Nicolas Angel Tinassi, 1671.

Hampe Martínez, Teodoro. Santidad e identidad criolla. Estudio del proceso de canonización de Santa Rosa. Centro de Estudios Regionales Andinos Bartolomé de las Casas, 1998.

Hansen, Leonardo. Vita mirabilis et mors pretiosa venerabilis sororis Rosae de S. Maria limensis, Ex Tertio Ordine S. P. Dominici, ad Sanctissimum D. N. Alexandrum VII. Pontificem Max. Nicolas Angel Tinassi, 1664.

Hart, Stephen M., editor. Edición crítica del Proceso apostólico de Santa Rosa de Lima (1630-1632): Congr. Riti Processus 1573, Archivum Secretum Vaticanum. Editorial Cátedra Vallejo, 2017.

------. Santa Rosa de Lima. La evolución de una santa (1586-1617). Traducido por Nadia Stagnaro, Editorial Cátedra Vallejo, 2017.

------. “The Biographical Fashioning of the Americas' First Saint: Santa Rosa de Lima (1586-1617)”. The Modern Language Review, vol. 114, n. ${ }^{\circ}$ 2, abril de 2019, pp. 230-258.

Iwasaki, Fernando. iAplaca, Señor, tuira!Lo maravilloso y lo imaginario en Lima colonial. Fondo de Cultura Económica, 2018.

Lavallé, Bernard. Las promesas ambiguas: ensayos sobre el criollismo colonial en los Andes. Pontificia Universidad Católica / Instituto Riva Agüero, 1993.

Meléndez, Juan. Tesoros verdaderos de las Yndias en la historia de la gran provincia de San Iuan Bautista del Peru de el Orden de Predicadores al Reverendissimo Padre F. Antonio de Monroy Mexicano, General del dicho Orden. Tomo II, Nicolás Ángel Tinassio, 1681. 
Millones, Luis. Una partecita del cielo. La vida de Santa Rosa de Lima narrada por el don Gonzalo de la Maza a quien ella llamaba padre. Editorial Horizonte, 1993.

Mujica Pinilla, Ramón. Rosa limensis. Mistica, política e iconografía en torno a la patrona de América. Instituto Francés de Estudios Andinos / Fondo de Cultura Económica / Banco Central de la Reserva del Perú, 2001.

Myers, Kathleen Ann. "Redeemer of America': Rosa de Lima (1586-1617), the Dynamics of Identity and Canonization". Colonial Saints. Discovering the Holy in the Americas, editado por Allan Greer y Jodi Bilinkoff, Routledge, 2003, pp. 251-275.

Parra, Jacinto de. La bienaventurada Rosa peruana de Santa Maria de la Orden de Santo Domingo. Su admirable vida y preciosa muerte. Traducido por L. Hansen, Melchor Sánchez, 1668.

Primer proceso ordinario para la canonización de Santa Rosa de Lima. Transcripción, introducción y notas de Hernán Jiménez Salas, Monasterio de Santa Rosa de Santa María de Lima, 2002.

Quevedo Alvarado, María Piedad. Un cuerpo para el espiritu: mistica en la Nueva Granada, el cuerpo, el gusto y el asco, 1680-1750. Instituto Colombiano de Antropología e Historia, 2007.

Ramos, Gabriela. Muerte y conversión en los Andes. Lima y Cuzco, 1532-1670. Instituto de Estudios Peruanos; Cooperación Internacional para los Países Andinos / Embajada de Francia; Instituto Francés de Estudios Andinos, 2010.

Rappaport, Joanne. The Disappearing Mestizo. Configuring Difference in the Colonial New Kingdom of Granada. Duke University Press, 2014.

Rocaberti, Juan Tomás de. Vida admirabley muerte preciosa de la venerable madre sóror Rosa de Santa Maríaperuana, en Lima, de la Tercera Orden de Predicadores. Sada del proceso remissorial, hecho con decreto de la santidad de Vrbano VIII. Escrita en latín e impresa en Roma por el MRPM Fr. Leonardo Hansen. Recopilada de orden del MRPM fr. Juan Tomas de Rocaberti. Gerónimo Vilagrasa, 1665.

Sales, San Francisco de. Introducción a la vida devota. 7. a ed., Ediciones Palabra, 1980.

Sánchez Concha, Rafael. Rosa de Santa María. Primera Santa de América. Municipalidad de Lima (Munilibros), 2017.

Vidal, Fernando. "Miracles, Science and Testimony in Post-Tridentine Saint-Making". Science in Context, vol. 20, n. ${ }^{\circ}$ 3, 2007, pp. 481-508.

Zevallos, Noe. Santa Rosa de Lima, compromiso y contemplación. CEP, 1987.

\section{Notas}

* Artículo de investigación.

1 Recordemos que Santa Rosa nació en Lima en 1586, fue bautizada con el nombre de Isabel Flores de Oliva, adquirió el nombre "Rosa” y el apellido "Santa María” por mediación divina. Adoptó el hábito de la Orden Tercera de los Dominicos. Falleció en 1617 y fue canonizada en 1671. Su primera biografía (o hagiografía) se publicó en latín en 1664 y contribuyó desde su léxico e imágenes a esa transformación de la Rosa limeña en una figura clásica. Stephen Hart ha apuntado el "giro clásico" del autor de esta primera biografía y que "con frecuencia invocó la mentalidad grecolatina al momento de elaborar la vida de Rosa" ( Santa Rosa 32). El presente artículo se concentra en la presencia indígena en el proceso de santidad de Rosa; aunque fue también notable la devoción de la comunidad de origen africano en este proceso.

2 La larga tradición de cercanía doméstica entre el mundo criollo e indígena que definió y fundó en buena parte la ciudad virreinal puede verse, indirectamente, en la película Roma del director mexicano Alfonso Cuarón (2018), un ensayo afectivo sobre la complicada relación, hacia 1970, de una familia de clase media alta en la Ciudad de México y su empleada doméstica.

3 Por ejemplo, la arquitectura y urbanística mantienen hasta hoy zonas de servicio doméstico en las modernas construcciones de apartamentos, diseñados para empleadas "con cama adentro".

4 El presente artículo forma parte de un trabajo más ambicioso con las variantes de estos documentos. El libro de Joanne Rappaport, The Disappearing Mestizo , es un excelente estudio de los archivos legales del Nuevo Reino de Granada que permite ver las variaciones del vocabulario racial colonial. La tradición visual sobre Santa Rosa es riquísima y no me ocuparé de ella en este trabajo, al que Ramón Mujica Pinilla le dedicó su notable Rosa limensis . El artículo de Kathleen Myers, “'Redeemer of America’: 
Rosa de Lima (1586-1617), the Dynamics of Identity and Canonization”, analiza los collages icono-léxicos hechos por Santa Rosa y el discurso criollo de su canonización. La santidad como performance de raza y género en Lima en el siglo XVII ha sido abordada en la tesis doctoral de Pilar Espitia, Queering the Andean Mystics: represiones, subversiones y deseos en las prácticas religiosas de la América colonial (Perú, siglos XVI-XVII) ; y el discurso del cuerpo - el gusto, el asco- en el misticismo en la Nueva Granada por María Piedad Quevedo Alvarado, Un cuerpo para el espiritu: mistica en la Nueva Granada, el cuerpo, el gusto y el asco 1680-1750 . Sobre el misticismo afroperuano femenino en Lima en el siglo XVII, véase Nancy E. van Deusen, Las almas del purgatorio: el diario espiritual y vida anónima de Úrsula de Jesús, una mistica negra del siglo XVII .

5 Resumo y simplifico en estas líneas los imprescindibles estudios de Teodoro Hampe, Santidad e identidad criolla y de Stephen M. Hart, particularmente su Santa Rosa de Lima (1586-1617): la evolución de una santa, su artículo de 2019 "The Biographical Fashioning of the Americas' First Saint: Santa Rosa de Lima (1586-1617)” y su Edición crítica del Proceso apostólico de Santa Rosa de Lima ; y sigo, también, la edición del Primer proceso ordinario para la canonización de Santa Rosa, hecha por Hernán Jiménez Salas. Sin estas publicaciones, el presente trabajo no podría sustentar sus hipótesis básicas. Asimismo, dejo aquí constancia de la importancia que, desde finales de la década de 1990, tuvieron los libros de Luis Millones Una partecita del cielo y el mencionado de Hampe para abrirme a nuevas lecturas sobre la figura de Santa Rosa y su densidad histórica. El libro de Millones, además de su estudio sobre los "años oscuros" de la santa y su relación con el mundo indígena, incluye una edición paleográfica del testimonio de Gonzalo de la Maza y un capítulo de Fernando Iwasaki sobre el entorno de las mujeres alumbradas en Lima, estudio que ha extendido y rescrito en su libro ;Aplaca, Señor, tu ira! Lo maravilloso y lo imaginario en Lima colonial.

6 En la traducción castellana de 1665 publicada en Valencia, el título especifica: "Sacada del proceso remisioral hecho con decreto de santidad de Urbano VIII". Véase Rocaberti.

7 Hart ha hecho un trabajo notable para introducir a Vincent Torre (alias L. Hansen) en la historia textual de Santa Rosa, a quien describe como "un fiero intelectual y un convencido de la disciplina inflexible" ( Santa Rosa 51-54; “The biographical” 249).

8 La nueva economía de los milagros se recoge en la obra del médico Paulo Zacchia, Quaestiones medico-legales (1621-1651). Véase Fernando Vidal y Hart (Santa Rosa 75-81).

9 Sobre Luisa Melgarejo y el entorno de las mujeres beatas, místicas y alumbradas, véase el capítulo IV, "Fábrica barroca”, de Fernando Iwasaki (219-387).

10 Sobre los cambios en los regímenes de enterramiento en Lima para las diferente naciones o grupos étnicos, véase Gabriela Ramos (182).

11 "A Toribio [de Mogrovejo] lo recibieron mal los pobladores y el descontento no pudo ser controlado. El párroco ya le había advertido que se trataba de una 'chusma idólatra' de '3000 almas', de las que solo pudo confirmar a tres, entre ellas a Santa Rosa” (Millones 46; la información la toma de Hansen). ¿Se habría confirmado Mariana junto con Rosa en Quives?

12 Prescindo, por supuesto, de numerosos detalles y matices de la vida de Rosa, que pueden seguirse desde las primeras hagiografías hasta los recientes estudios y biografías, como los publicados por José Antonio del Busto en 2006, el libro ya mencionado de Hart y el de Rafael Sánchez Concha Barrios, publicado en 2017. El libro de Hampe de 1998 incluye un resumen biográfico (11-18) y el de Mujica Pinilla de 2007 una útil cronología (373-379). En todo caso, hay no pocas fechas que son aproximadas. La biografía latina de Hansen - y todas las que lo traducen o adaptan en el siglo XVII- no sigue una estructura cronológica.

13 Fardero: probablemente el cargador de fardos, es decir, de mercancías atadas con un lienzo. No se menciona que fuera indígena, pero es presumible.

14 Es decir, nacida en Lima y castellanohablante (por eso criolla) e india de nación (natural). El término ladino no se usaba en primera persona. Dejo para otra ocasión el comentario sobre lo "natural y criollo" y la importancia de ser castellanohablante en su autodefinición. En 1617, las preguntas del PO describen a la madre de Rosa como "criolla natural de esta ciudad de los Reyes" (20; el énfasis es mío), mientras que en 1631 ya no se usa criolla para describirla (Hart, Edición crítica 172 [PA]). Véase Lavallé sobre los usos tempranos de criollo en Perú.

15 Manta: era el puerto de Puerto Viejo, en el litoral ecuatorial, y era el nombre de una antigua etnia o "nación”.

16 El testimonio del PA fue sin duda una de las fuentes de Hansen y Parra. No he podido acceder todavía a los manuscritos del PO y PA, guardados en el Archivum Secretum Vaticanum y el Archivo Arzobispal de Lima. La monumental edición de Hart es utilísima; presenta el texto modernizado, siguiendo el mismo criterio del padre Jiménez en su edición del PO. La edición crítica de Hart contiene algunas erratas, que pueden corregirse por el sentido, como "deshecha" por "derecha" (182); "alimento" por "tullimiento" (414); "un amigo" por "un castigo" (528); "madera de cárcel” por "madera de cancel” (555), etc. 
17 El episodio lo cuenta también el criollo González de Acuña en su Rosa mística. Dice que Mariana había ido a visitar a la enferma, sin dar información del barrio, pero no dice que Vela le haya pedido el retrato de Rosa; en cambio, presenta a Mariana como alguien con iniciativa: "La india con diligencia se fue a su casa, trajo un retrato" (325). En la versión de Ferrer Valdecebro, Mariana llegó de visita ya con el retrato de Rosa (495).

18 Según la madre, Rosa sufrió entre los 12 y los 13 años de esta enfermedad ( Primerproceso 386 [PO]). En este episodio no debe descartarse que la madre siguiera alguna recomendación indígena para aplicar los pellejos de buitre (¿cóndor?) con fines curativos.

19 Millones compartía el interés por los estudios sobre Santa Rosa con Noe Zevallos, quien publicó en 1987 su breve libro Santa Rosa de Lima, compromiso y contemplación, donde presta también atención a la experiencia de la joven Rosa en el pueblo de Quives, llamado hoy Santa Rosa de Quives.

20 Millones cita a Hansen y la traducción incluida en el tomo II de los Tesoros verdaderos de las Indias de Juan Meléndez. Sin embargo, Meléndez — que realmente reedita la traducción y adaptación hecha por Ferrer Valdecebro (1666) — le da un importante matiz criollo a esta visión "agreste" de los indios.

21 Son muy conocidos el "descubrimiento" y denuncia que hizo el padre Francisco de Ávila en 1607 de las "idolatrías" en Huarochirí (en la sierra de Lima), la quema de las guacas u objetos indígenas tenidos por idolátricos que este dirigió en la plaza de Lima, y el inicio de las severas campañas de extirpación de idolatrías en 1610. Véase Estenssoro (333-370).

22 Jiménez Salas, en su edición del PO, transcribe: "Mariana de Oliva su criada, y secretaría de la bendita santa" (f. 300v). La palabra debe leerse secretaria, femenino de secretario: 'Oficio de mucha confianza cerca de los reyes y sus concejos, en todos los tribunales y entre señores particulares' (Covarrubias, s. v. Secreto). Hart entiende la palabra secretaria en un sentido restrictivo, vinculado a la escritura, que no se sostiene en estos documentos (Edición crítica 44 [PA]).

23 Mariana recuerda que la mudanza de Rosa ocurrió "cinco años antes de que muriese" (Hart, Edición crítica 415 [PA]). Gonzalo de Maza declaró en 1617 que unos cinco años atrás "lo más del tiempo habitó la dicha Rosa de Santa María en casa de este testigo" ( Primer proceso 46 [PO]).

24 José de Acosta, en su Historia moral y natural de las Indias, menciona la papa como un ingrediente base del locro, "cierto guisado o cazuela" (285). Es voz quechua, en su variante costeña. Este testimonio de la madre de Rosa puede ser la primera evidencia del guisado del locro en una familia criolla limeña hacia 1600.

25 Catalina de Jesús, monja profesa de velo negro de la Santísima Trinidad, quien conoció a Rosa desde 1609, recuerda también haber visto los "locrillos" con hojas de granadilla, pero no menciona a Mariana ( Primer proceso 393 [PO]). Sobre los diminutivos, Mariana dice también "sillita", "cerrojito", entre otros ( Primer proceso 408 [PO]). Creo que, a pesar de todas las intervenciones presumibles en la producción de los documentos para la canonización, el testimonio de Mariana mantiene algunos rasgos de la personalidad lingüística de la "criada india".

26 La palabra ají aparece en el testimonio de Mariana de 1631 como "ají fuerte de chile [sic]" (Hart, Edición crítica 413[PA]). Es evidente que, en la transcripción de los testimonios o deposiciones orales y en su preparación para que fueran leídos en España, intervinieron varias manos para explicar, glosar o eliminar las palabras en quechua. No me detengo aquí a comentar la riqueza léxica de estos materiales, que merecen un extenso estudio desde los manuscritos.

27 El uso de "mora" para adjetivar a "Mariana india" es probablemente un error por "moza". La madre de Rosa se refiere a sí misma, cuando joven, con ese mismo adjetivo "mora" (Hart, Edición crítica 185). Como no he podido consultar todavía los manuscritos, no me detengo aquí en estas particularidades del PA. El milagro que se cuenta a continuación es la curación de un religioso herido en la muñeca al sacar la silla de la celda de Rosa. Se curó gracias a un pedazo de hábito de la santa. Mariana no interviene en este segundo milagro. Algunas características textuales nos sugieren que este testimonio sería un resumen corregido por los superiores dominicos de la madre-monja.

28 El libro de San Francisco de Sales se publicó por primera vez en 1608 en francés, y en castellano en 1618.

\section{Licencia Creative Commons CC BY 4.0}

Cómo citar este artículo: Firbas, Paul. "Mariana de Oliva, criada india de Santa Rosa de Lima: vida y textos". Cuadernos de Literatura, vol. 25, 2021. https://doi.org/10.11144/Javeriana.cl25.moci 